\title{
Local Strain Fields of LPSO in Mg-Based Ternary Alloys
}

\author{
Shuhei Matsunaga ${ }^{1, *}$, Takanori Kiguchi ${ }^{2}$, Kazuhisa Sato $^{2}$ and Toyohiko J. Konno ${ }^{2}$ \\ ${ }^{1}$ Department of Materials Science, Graduate School of Engineering, Tohoku University, Sendai 980-8579, Japan \\ ${ }^{2}$ Institute for Materials Research, Tohoku University, Sendai 980-8577, Japan
}

\begin{abstract}
$\mathrm{L}_{2}$-type $\mathrm{TM}_{6} \mathrm{RE}_{8}$ clusters are distributed in enriched layers of LPSO (long period stacking ordered structure), and shrink in the [0001 $]_{\mathrm{Mg}}$ direction. The growth mechanism of LPSOs was investigated from the viewpoint of a local strain field. The strength of out-of plane normal strain of the enriched layer varied with the average radius of solute elements in the layer. The first principle calculation showed that there is a relationship between the average atomic radius of solute elements and the structural relaxation in the clusters. Zn conclusion, it is suggested that the difference of average atomic radius between $\mathrm{Mg}$ and solute elements controls the degree of the cluster shrinkage by the displacement of the solute elements, and that it is the dominant factor giving rise to the out-of plane normal strains of the enrichment layers. [doi:10.2320/matertrans.MH201404]
\end{abstract}

(Received January 23, 2015; Accepted March 24, 2015; Published May 22, 2015)

Keywords: magnesium alloy, long-period stacking ordered structure, local strain, atomic radius, scanning transmission electron microscopy

\section{Introduction}

Magnesium based alloys are attractive as next-generation lightweight structural materials. In particular, a series of novel structures, so-called "synchronized long period stacking ordered structure (LPSO)" in Mg-TM-RE (TM and RE respectively stand for transition and rare earth metals) alloy systems is known for giving remarkable mechanical properties. $^{1-3)}$ It is believed that TM and RE elements are both segregated into stacking faults, as in the case of the Suzuki effect, and then the segregated stacking faults piles up, finally giving rise to a long-range order.

The atomic level structure of LPSOs has been examined by many researchers. Four polytype, $10 \mathrm{H}, 14 \mathrm{H}, 18 \mathrm{R}$ and $24 \mathrm{R}$ LPSOs were found in the Mg-Zn-Y alloys, depending on the thermal history and the solute concentration. ${ }^{4-8)}$ Recently, we have shown the elementary steps of the transformation among the polytypes in aged $\mathrm{Mg}_{97} \mathrm{Zn}_{1} \mathrm{Y}_{2}$ alloys at the atomic level. ${ }^{9)}$ However, as to the formation and growth process prior to the transformation, a number of issues still remains unsolved. For example, Yokobayashi et al. and Egusa et al. have shown that TM and RE elements form $\mathrm{L1}_{2}$-type clusters in the enriched layers of OD structures and LPSOs, respectively. ${ }^{10,11)}$ Egusa et al. also revealed using a first principle calculation that the $\mathrm{L}_{2}$-type $\mathrm{Zn}_{6} \mathrm{Y}_{8}$ clusters shrink in the enriched layer. ${ }^{10)} \mathrm{We}$ have already investigated that the local strain fields accompanying LPSOs, and revealed that the normal strain field was formed in the $[0001]_{\mathrm{Mg}}$ direction in LPSOs. ${ }^{9)}$ These studies have shown that a local strain field is created in the $[0001]_{\mathrm{Mg}}$ direction in LPSOs, and it was suggested that the strain field is affected by the shrinkage of the clusters. In the present study, we have investigated that the relationship between the local strain fields and LPSO polytypes, and the effect of apparent radius of solute elements on the shrinkage of clusters and local strain in LPSOs.

\section{Experimental Procedures}

The Mg-TM-RE alloy ingots were prepared using a high-

*Graduate Student, Tohoku University frequency induction casting method in an argon atmosphere. The nominal composition of the alloys used in this study were $\mathrm{Mg}_{97} \mathrm{Zn}_{1} \mathrm{Y}_{2}, \mathrm{Mg}_{97} \mathrm{Zn}_{1} \mathrm{Gd}_{2}, \mathrm{Mg}_{97} \mathrm{Zn}_{1} \mathrm{Er}_{2}$ and $\mathrm{Mg}_{93.5} \mathrm{Ni}_{3}-$ $\mathrm{Y}_{3.5}$ (at\%). The ingots were aged at $773-843 \mathrm{~K}$ for $5-30 \mathrm{~h}$ in argon atmosphere and then quenched in ice water. Microstructural analyses were conducted by a conventional transmission electron microscopy (TEM) and an aberrationcorrected scanning transmission electron microscopy (STEM) (JEM-ARM200F, $200 \mathrm{kV}$, JEOL). The estimated collection semi-angle range of high-angle annular dark field (HAADF)-STEM images was set to $90-175 \mathrm{mrad}$. The estimated convergent semi-angle used for HAADF-STEM observation was $23 \mathrm{mrad}$. This foils for (S)TEM observation were thinned using mechanical polishing followed by lowenergy ion milling from $5 \mathrm{kV}$ to $200 \mathrm{~V}$ (PIPS model1691, Gatan). The HAADF-STEM images were filtered using Wiener and Bragg filtering to improve the image quality without periodic artifacts (Filter Pro, HREM Research). Local strain analysis was conducted using peak pairs analysis (PPA) of the HAADF-STEM images (PPA, HREM Research). ${ }^{12)}$ Reference area for the analysis was set to the hexagonal closed pack (HCP)-type stacking region in the matrix or LPSO.

\section{Results and Discussion}

Figure 1 shows (a) a HAADF-STEM image of edge region of LPSO in the $\mathrm{Mg}_{97} \mathrm{Zn}_{1} \mathrm{Y}_{2}$ aged at $773 \mathrm{~K}$ for $10 \mathrm{~h}$; strain map around the edge region of a LPSO of (b) in-plane normal strain, (c) out-of plane normal strain, and (d) pure shear strain. The image (a) shows that the growth direction of the enriched layers is parallel to $(0001)_{\mathrm{Mg}}$. The strain map (b) shows a homogeneous contrast within $\pm 0.3 \%$, which means that the interface between the enriched layer and the nonenriched layer is coherent. The strain map (c) shows that the enriched layers of LPSO are contracted by $10 \%$ in the $[0001]_{\mathrm{Mg}}$ direction, while the non-enriched layers are elongated by $5 \%$ in the same direction. It crearly shows that the overall strain is relaxed within the LPSO, and then there is no effects of the strain field on the matrix region. Figure 1(d) shows that there is HCP-type region at the edge 

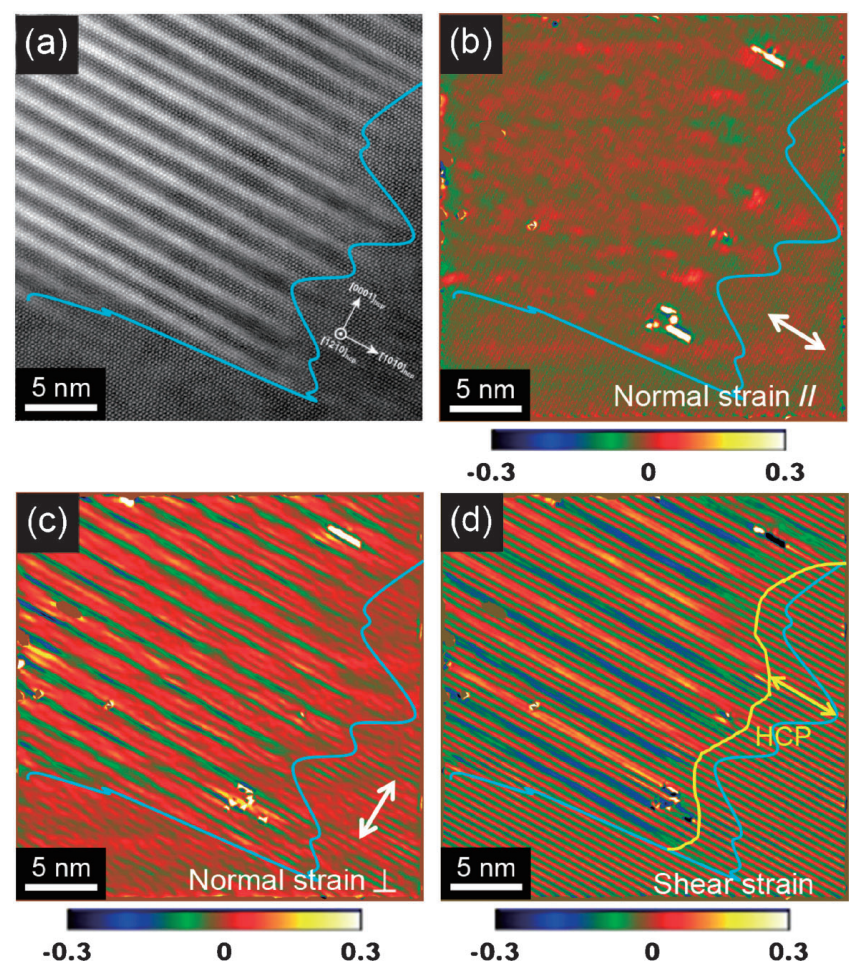

Fig. 1 (a) HAADF-STEM image of the $\mathrm{Mg}_{97} \mathrm{Zn}_{1} \mathrm{Y}_{2}$ aged at $773 \mathrm{~K}$ for $10 \mathrm{~h}$, strain maps of (b) in-plane normal strain, (c) out-of plane normal strain, and (d) shear strain around the edge region of a LPSO band.

of LPSO. In this region, contraction is occurred but the slip is not observed. This result infers, on first glance, that the growth of LPSO is promoted by the solute-enriched HCPtype structure. However, the edge of LPSO shows a superimposed structure of the solute-enriched layers with face centered cubic (FCC)-type stacking sequence and the matrix layer with HCP-type one, because LPSO would have acute-angled edge structure. It is necessary for the further detailed analysis for the interpretation of the Z-contrast of the edge structure of LPSO.

Figure 2(a) shows a HAADF-STEM image of $\mathrm{Mg}_{97} \mathrm{Zn}_{1} \mathrm{Y}_{2}$ aged at $843 \mathrm{~K}$ for $5 \mathrm{~h}$. There are two enriched layers along $(0001)_{\mathrm{Mg}}$ plane. The bright and sharp contrast layer has the FCC-type structure, while weak contrast one HCP-type structure. Figure 2(b) shows the in-plane normal strain map around the two enriched layers obtained from the PPA of the HAADF-STEM image. Both layers are coherent with the matrix, as also shown in Fig. 1(b). The out-of plane normal strain map (c) and the intensity profile (d) show that the enriched layers are contracted in the $[0001]_{\mathrm{Mg}}$ direction compared with the matrix. That is, the FCC-type layer is contracted by about $10 \%$. The HCP-type layer is contracted by about $6 \%$, however, it is necessary to conclude the value is essential or not based on the Z-contrast interpretation by further investigation.

Figure 3(a) shows an enlarged image around the FCC-type layer. In this image, it can be seen that the layers adjacent to the enriched layers are elongated in the $[0001]_{\mathrm{Mg}}$ direction to relax strain. The elongation of the adjacent layers is about $5 \%$ around both layers. Figure 3(b) is a schematic model of strain field around the enriched layer. It is suggested that the strain extends to two of three atomic columns on both sides of the
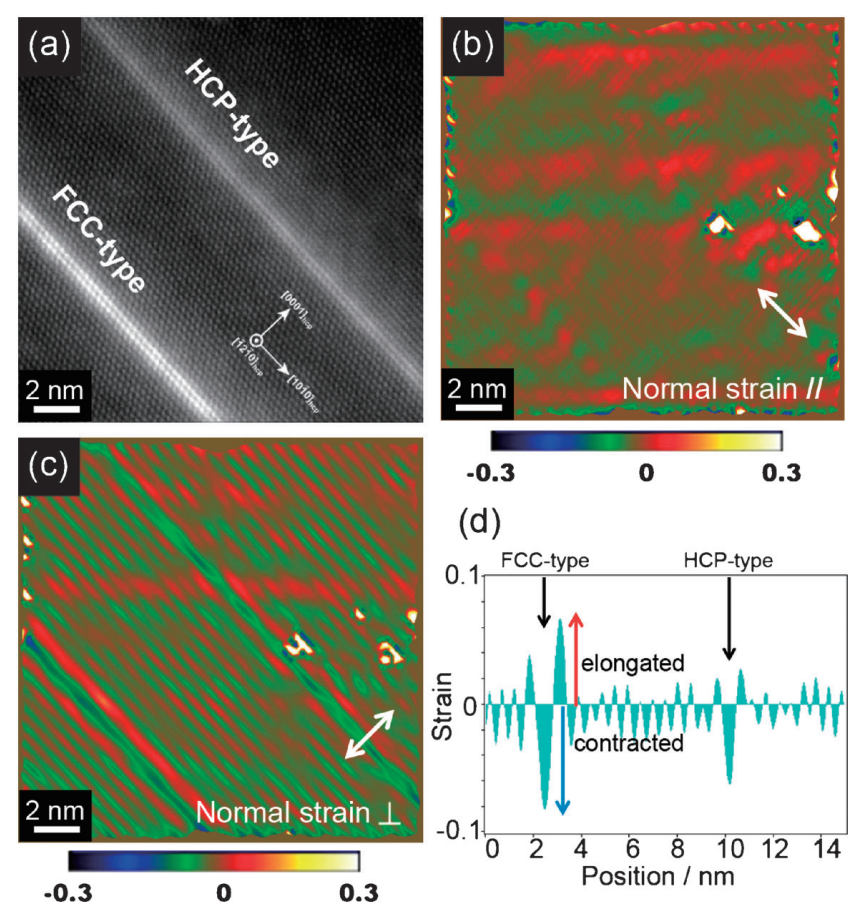

(d)

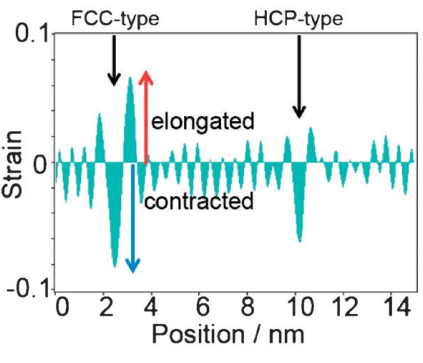

Fig. 2 (a) HAADF-STEM image of $\mathrm{Mg}_{97} \mathrm{Zn}_{1} \mathrm{Y}_{2}$ aged at $843 \mathrm{~K}$ for $5 \mathrm{~h}$, strain maps of (b) in-plane normal strain, and (c) out-of plane normal strain. (d) Intensity profile of out-of plane normal strain map (c) along the $[0001]_{\mathrm{Mg}}$ direction.
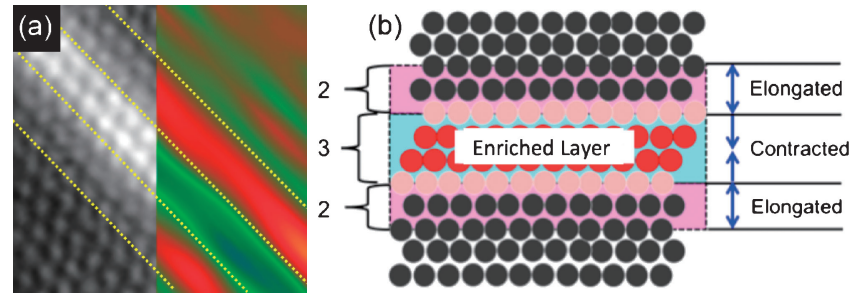

Fig. 3 (a) Enlarged image around the FCC-type layer. (b) Schematic model of strain field around the enriched layer.

layer. This result indicates that the elongated non-enriched layers neighbor the each enriched layers overlap each other within a LPSO. The order of the elastic interaction between solute enriched layers is as follows: 10H-type $>18 \mathrm{R}-$ type $>14 \mathrm{H}$-type LPSOs with 1, 2, 3 non-enriched layers, respectively. The 24R-type is excluded since it is observed just as a irregular stacking within the quasi-stable 18R-LPSO band. ${ }^{9)}$ This fact implies that the elastic stability of LPSOs is highest in $14 \mathrm{H}$-type and lowest in $10 \mathrm{H}$-type by the elastic interaction.

In fact, the Mg alloys with lower solute concentration such as $\mathrm{Mg}_{97} \mathrm{Zn}_{1} \mathrm{Y}_{2}$ alloys forms 18R-type LPSO and transforms into $14 \mathrm{H}$-type one, or $\mathrm{Mg}_{97} \mathrm{Zn}_{1} \mathrm{Gd}_{2}$ directly forms $14 \mathrm{H}$-type one. $^{8-10)}$ On the other hand, those with higher solute concentration such as $\mathrm{Mg}_{85} \mathrm{Zn}_{6} \mathrm{Y}_{9}$ alloys forms $18 \mathrm{R}$ - and $10 \mathrm{H}$-type LPSO and transforms into $10 \mathrm{H}$-type. ${ }^{10)}$ Recently, $\mathrm{Mg}_{75} \mathrm{Zn}_{10} \mathrm{Y}_{15}$ alloys also forms 18R- and 10H-type LPSO and transforms into completely ordered $10 \mathrm{H}$-type one, which is OD structure. ${ }^{13}$ ) The density of the solute elements or clusters in an enriched layer increased and the number of non-enriched layers decreased with increment of the nominal 

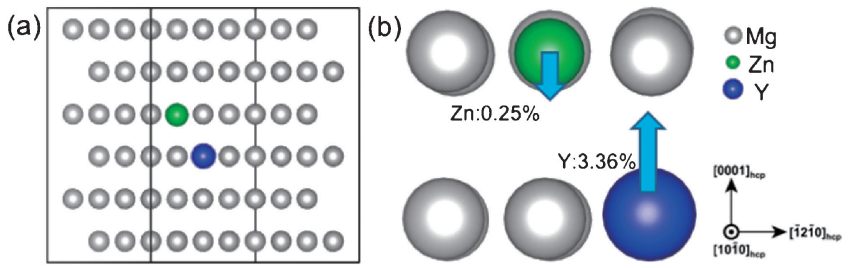

Fig. 4 (a) Initial model structure of $\mathrm{Zn}-\mathrm{Y}$ pair embedded in the HCP-Mg matrix. (b) Local structure around the $\mathrm{Zn}-\mathrm{Y}$ pair in energetically optimized structure model.

composition of the solute elements. The opposing force of these chemical interaction and the elastic interaction would effect the stability of LPSOs under the given composition.

Figure 2 also shows that the degree of contraction of the enriched layers in the $[0001]_{\mathrm{Mg}}$ direction varies with the stacking types. Egusa et al. reported using the first principle calculation that the $\mathrm{Zn}_{6} \mathrm{Y}_{8}$ ( $\mathrm{Ll}_{2}$-type) cluster exhibited relaxation. ${ }^{10)}$ Namely, the cluster shrinks in the $[0001]_{\mathrm{Mg}}$ direction about $11.5 \%$, which is close to the value of our result. In order to consider a lattice strain in the HCP-type layer, we constructed a model, where $\mathrm{Zn}$ and $\mathrm{Y}$ atoms exist in the $\mathrm{Mg}$ matrix, then modeled a structural relaxation. According to Nishitani et al., Zn-Y atomic pair is more stable than $\mathrm{Mg}-\mathrm{Zn}$ or Mg-Y pair. ${ }^{14)}$ In the model, $2 \mathrm{H}$-type $\mathrm{Mg}$ matrix is extended to $4 \times 4 \times 3$ and adjoining two $\mathrm{Mg}$ atoms are replaced by $\mathrm{Zn}$ and $\mathrm{Y}$ atoms (Fig. 4(a)). We applied this model and calculated structural relaxation on the condition that $\mathrm{k}$-mesh is Gamma $3 \times 3 \times 3$. Our result shows that $\mathrm{Zn}$ and $\mathrm{Y}$ atoms approach each other in the optimized structure, as shown in Fig. 4(b). The displacement values of $\mathrm{Zn}$ and $\mathrm{Y}$ atoms in the $[0001]_{\mathrm{Mg}}$ direction compared with $\mathrm{Mg}$ matrix are $0.3 \%$ and $3.4 \%$, respectively. In other words, local lattice spacing is contracted about $3.7 \%$ because of interatomic force of two solute atoms. From the above results, the HCPtype enriched layer also has strain fields in the out-of-plane direction. The strain is smaller than that of $\mathrm{L}_{2}$ (FCC)-type cluster, however, this result still corresponds to the PPA result shown in Fig. 2.

Figure 5 shows (a)(d) HAADF-STEM images of LPSO in the $\mathrm{Mg}_{97} \mathrm{Zn}_{1} \mathrm{Y}_{2}$ aged at $773 \mathrm{~K}$ for $30 \mathrm{~h}$ and $\mathrm{Mg}_{97} \mathrm{Zn}_{1} \mathrm{Gd}_{2}$ aged at $773 \mathrm{~K}$ for $5 \mathrm{~h},(\mathrm{~b})(\mathrm{e})$ the Bragg filtered HAADF-STEM images of $(\mathrm{a})(\mathrm{d})$ and out-of plane normal strain maps obtained from the images, and (c)(f) intensity profiles of the rectangle region indicated in the strain maps (b)(e). Figure 5(a) shows most of the LPSO is 14H-type. Figure 5(c) shows that the contraction of the enriched layers of LPSO in the $\mathrm{Mg}_{97} \mathrm{Zn}_{1} \mathrm{Y}_{2}$ is about $8 \%$, as deduced from the value of the non-enriched layer. Note that this value is smaller than that of 18R-LPSO. ${ }^{9)}$ Figure 5(d) similarly shows the existence of 14H-type LPSO. Figure 5(f) shows that the contraction of the enriched layers of LPSO in the $\mathrm{Mg}_{97} \mathrm{Zn}_{1} \mathrm{Gd}_{2}$ is about $9 \%$, which is as same as that obtained for the layers in the $\mathrm{Mg}_{97} \mathrm{Zn}_{1} \mathrm{Y}_{2}$.

Figure 6 shows (a)(d) HAADF-STEM images of LPSO in the $\mathrm{Mg}_{97} \mathrm{Zn}_{1} \mathrm{Er}_{2}$ aged at $773 \mathrm{~K}$ for $10 \mathrm{~h}$ and the $\mathrm{Mg}_{93.5} \mathrm{Ni}_{3} \mathrm{Y}_{3.5}$ aged at $793 \mathrm{~K}$ for $5 \mathrm{~h}$, (b)(e) the Bragg filtered HAADFSTEM images of (a)(d) and out-of plane normal strain maps obtained from the images, and (c)(f) intensity profiles of
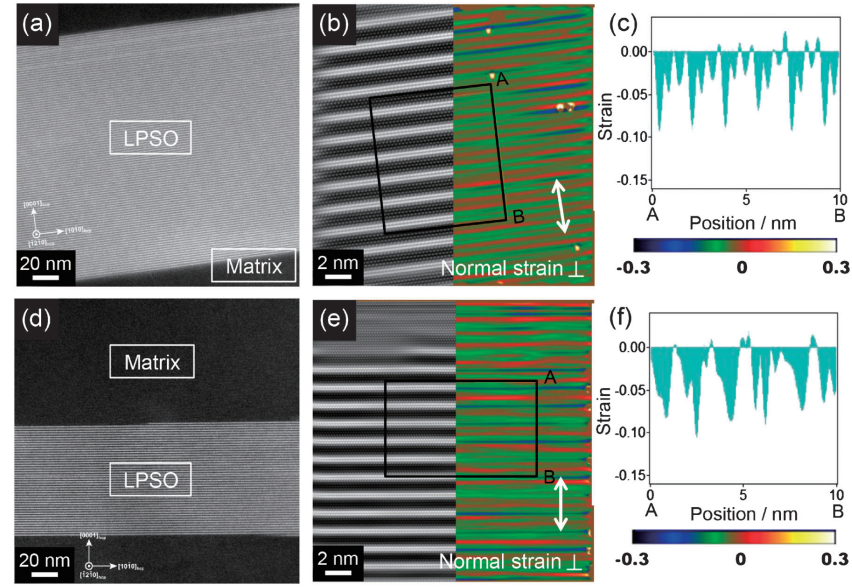

Fig. 5 (a)(d) HAADF-STEM images of LPSO in the $\mathrm{Mg}_{97} \mathrm{Zn}_{1} \mathrm{Y}_{2}$ aged at $773 \mathrm{~K}$ for $30 \mathrm{~h}$ and $\mathrm{Mg}_{97} \mathrm{Zn}_{1} \mathrm{Gd}_{2}$ aged at $773 \mathrm{~K}$ for $5 \mathrm{~h}$, (b)(e) the Bragg filtered HAADF-STEM images of (a)(d) and out-of plane normal strain maps obtained from the images, and (c)(f) intensity profiles of the rectangle region indicated in the strain maps (b)(e).
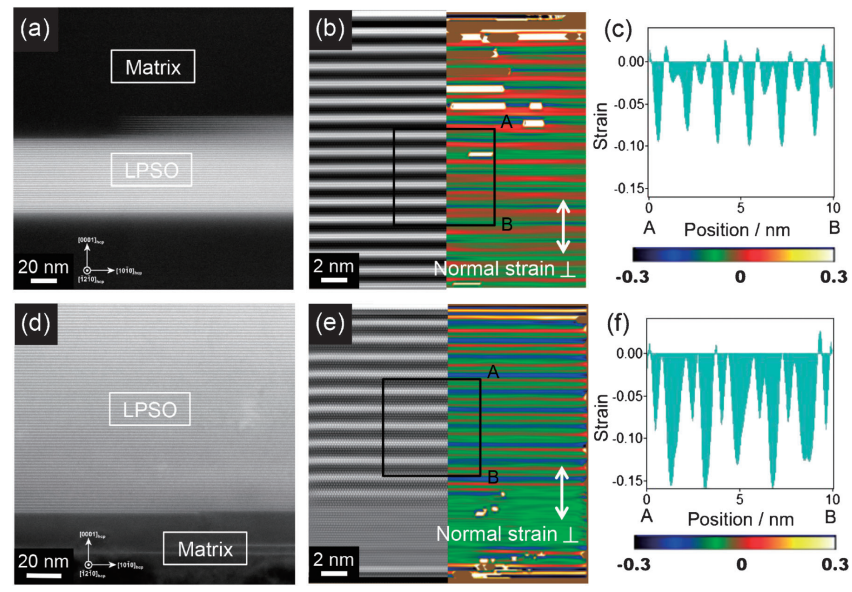

Fig. 6 (a)(d) HAADF-STEM images of LPSO in the $\mathrm{Mg}_{97} \mathrm{Zn}_{1} \mathrm{Er}_{2}$ aged at $773 \mathrm{~K}$ for $10 \mathrm{~h}$ and the $\mathrm{Mg}_{93.5} \mathrm{Ni}_{3} \mathrm{Y}_{3.5}$ aged at $793 \mathrm{~K}$ for $5 \mathrm{~h}$, (b)(e) the Bragg filtered HAADF-STEM images of (a)(d) and out-of plane normal strain maps obtained from the images, and (c)(f) intensity profiles of the rectangle region indicated in the strain maps (b)(e). (a) 0000000000000000000 0000000000000000000 0000000000000000000 ○०0000 Q RE1 0000000000 0000000000000000000 0000000000000000000 000000 RE2 00000000000 0000000000000000000 0000000000000000000
0000000000000000000 (b)

0000000000000000000 0000000000000000000 0000000000000000000 O Mg 0000000000000000000 - TM OCS80DR RE18000088000

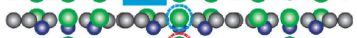
000000000000000000 $000000 d_{\text {RE } 2} 0000000000$ 0000000000000000000 , 000000000000000000

Fig. 7 Proposed structure in the enrichment layer of LPSO (a) before and (b) after structural relaxation. The $\mathrm{L1}_{2}$-type clusters are embedded in the $\mathrm{Mg}$ matrix.

the rectangle region indicated in the strain maps (b)(e). Figure 6(c) shows that the contraction of the enriched layers of LPSO in $\mathrm{Mg}_{97} \mathrm{Zn}_{1} \mathrm{Er}_{2}$ is about $11 \%$, where $\mathrm{RE}$ is changed from $\mathrm{Y}$ or $\mathrm{Gd}$ to $\mathrm{Er}$, is larger than that of $\mathrm{Mg}_{97} \mathrm{Zn}_{1} \mathrm{Y}_{2}$ or $\mathrm{Mg}_{97} \mathrm{Zn}_{1} \mathrm{Gd}_{2}$. In addition, in case of the $\mathrm{Mg}_{93.5} \mathrm{Ni}_{3} \mathrm{Y}_{3.5}$, the contraction of the enriched layers of LPSO is $14 \%$, which is 
Table 1 Calculated displacement of RE atoms in the enrichment layer.

\begin{tabular}{ccccc}
\hline \multirow{2}{*}{ Atoms } & \multicolumn{4}{c}{ Displacement, \% (+: shrinkage) } \\
\cline { 2 - 5 } & $\mathrm{Mg}-\mathrm{Zn}-\mathrm{Y}$ & $\mathrm{Mg}-\mathrm{Zn}-\mathrm{Gd}$ & $\mathrm{Mg}-\mathrm{Zn}-\mathrm{Er}$ & $\mathrm{Mg}-\mathrm{Ni}-\mathrm{Y}$ \\
\hline RE1 & 7.0 & 7.0 & 7.7 & 8.1 \\
RE2 & 17.7 & 17.2 & 20.3 & 20.2 \\
RE1 $\times 2$ & 14.0 & 14.0 & 15.4 & 16.2 \\
\hline
\end{tabular}

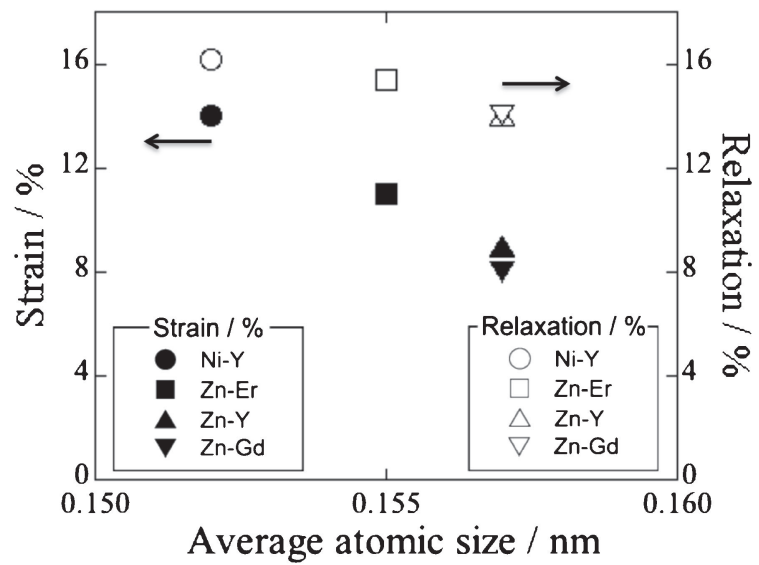

Fig. 8 Relationship between average atomic size of TM-RE pairs and results of the strain analysis and the structural relaxation.

larger than that of Mg-Zn-RE alloys as shown in Fig. 6(f). These results then suggest that the sort of solute elements of alloys modulate the out-of normal strain fields, the spacing of the basal planes in the enriched layers, between the enriched layers and the non-enriched layers of LPSO.

The effects of structural relaxation were evaluated by using the first principle calculation. Figure 7 shows that the proposed structure seen from $[10 \overline{1} 0]_{\mathrm{Mg}}$ in the enriched layers of LPSO (a) before and (b) after structural relaxation. From these figures, it is seen that $\mathrm{RE}$ atoms in $\mathrm{L1}_{2}$-type clusters, which consist of TM and RE atoms, move in the $[0001]_{\mathrm{Mg}}$ direction, i.e., to the center of the clusters. Conversely, TM atoms move in the $[0001]_{\mathrm{Mg}}$ direction, i.e., to the outside of the clusters. Table 1 shows displacements of RE atoms in clusters by the structural relaxation. The displacements decide the spacing of the basal planes of the solute enriched layers. The difference between before and after relaxation is small for the Mg-Zn-RE systems, however, it is larger for the $\mathrm{Mg}-\mathrm{Ni}-\mathrm{Y}$ system. Figure 8 shows the relationship between average atomic size of TM-RE pairs and the measured strain or the structural relaxation. From this diagram, it can be seen that the tendencies of the measured strain and the computed structural relaxation are well matched under the same average atomic size. Therefore, it is suggested that the difference of atomic radius between $\mathrm{Mg}$ and apparent solute atoms with the average atomic radius is the cause of the cluster shrinkage, and consequently it influences on the normal strain of in each LPSO band.

Here, Fig. 8 shows that the measured strain values are smaller than the calculated relaxation value of solute atom displacements. The model structure used for our calculation is simplified in the $\mathrm{L1}_{2}$-type $\mathrm{TM}_{6} \mathrm{RE}_{8}$ cluster array, which is ordered in-plane and out-of plane directions of the solute enriched layers. On the other hand, the clusters in the used alloys does not have ordered array completely. The alloys also used in this study have lower concentration of solute elements and relatively short aging period. The degree of the cluster ordering and/or the density of the cluster are lower than that of the model structure. Therefore, the elastic interaction between clusters or solute enriched layers may be overestimated.

\section{Conclusions}

This study has elucidated the local strain fields in LPSO bands and solute enriched layers using HAADF-STEM and the related local strain analysis, and the effect of the average atomic size of solute elements on the local strain field in LPSO bands, in atomic scale.

(1) The enriched layers composed of solute elements are contracted and the non-enriched layers are expanded in the $[0001]_{\mathrm{Mg}}$ direction, with respect to the matrix region. The overall strain is relaxed within each LPSO, and then there is almost no effect on the strain field of the matrix region.

(2) The contraction of the enriched layers of LPSO in $\mathrm{Mg}_{97} \mathrm{Zn}_{1} \mathrm{Er}_{2}$, where RE is changed from Y or Gd to Er, is larger than that of $\mathrm{Mg}_{97} \mathrm{Zn}_{1} \mathrm{Y}_{2}$ or $\mathrm{Mg}_{97} \mathrm{Zn}_{1} \mathrm{Gd}_{2}$. In case of the $\mathrm{Mg}_{93.5} \mathrm{Ni}_{3} \mathrm{Y}_{3.5}$, the contraction is larger than that of Mg-Zn-RE. It is suggested that apparent atomic radius difference between $\mathrm{Mg}$ and solute elements leads to the cluster shrinkage, and consequently result in the formation of normal strain fields of the enriched layers in each LPSO band.

\section{Acknowledgements}

This work was supported by a Grant-in-Aid for scientific Research on Innovative Areas "Synchronized Long-Period Stacking Ordered Structure $\sim$ The Evolution of the Material Science for Innovative Development of the Next-generation Lightweight Structure Materials " (23109006) from the Ministry of Education, Culture, Sports, Science and Technology (MEXT), Japan. The ingots were supported by Kawamura laboratory, Kumamoto University. The electrodischarge machining of the ingots was supported by Mr. Manabu Itoh, Institute for Materials Research, Tohoku University. The usage of electron microscopy was supported by Dr. Kosei Kobayashi, School of Engineering, Tohoku University.

\section{REFERENCES}

1) Y. Kawamura, K. Hayashi, A. Inoue and T. Masumoto: Mater. Trans. 42 (2001) 1172-1176.

2) A. Inoue, Y. Kawamura, M. Matsushita, K. Hayashi and J. Koike: J. Mater. Res. 16 (2001) 1894-1900.

3) E. Abe, Y. Kawamura, K. Hayashi and A. Inoue: Acta Mater. 50 (2002) 3845-3857.

4) T. Itoi, T. Seimiya, Y. Kawamura and M. Hirohashi: Scr. Mater. 51 (2004) 107-111.

5) M. Matsuda, S. Ii, Y. Kawamura, Y. Ikuhara and M. Nishida: Mater. Sci. Eng. A 393 (2005) 269-274. 
6) Y. M. Zhu, M. Weyland, A. J. Morton, K. Oh-ishi, K. Hono and J. F. Nie: Scr. Mater. 60 (2009) 980-983.

7) Y. M. Zhu, A. J. Morton and J. F. Nie: Acta Mater. 58 (2010) 29362947.

8) E. Abe, A. Ono, T. Itoi, M. Yamasaki and Y. Kawamura: Philos. Mag. Lett. 91 (2011) 690-696.

9) T. Kiguchi, Y. Ninomiya, K. Shimmi, K. Sato and T. J. Konno: Mater. Trans. 54 (2013) 668-674.

10) D. Egusa and E. Abe: Acta Mater. 60 (2012) 166-178.
11) H. Yokobayashi, K. Kishida, H. Inui, M. Yamasaki and Y. Kawamura: Acta Mater. 59 (2011) 7287-7299.

12) P. Galindo, S. Kret, A. M. Sanchez, J.-Y. Laval, A. Yanez, J. Pizzaro, E. Guerrero, T. Ben and S. I. Molina: Ultramicroscopy 107 (2007) 11861193.

13) M. Yamasaki, M. Matsushita, K. Hagihara, H. Izuno, E. Abe and Y. Kawamura: Scr. Mater. 78-79 (2014) 13-16.

14) Y. Yamamoto, Y. Sakamoto, Y. Masaki and S. Nishitani: Mater. Trans. 54 (2013) 656-660. 